
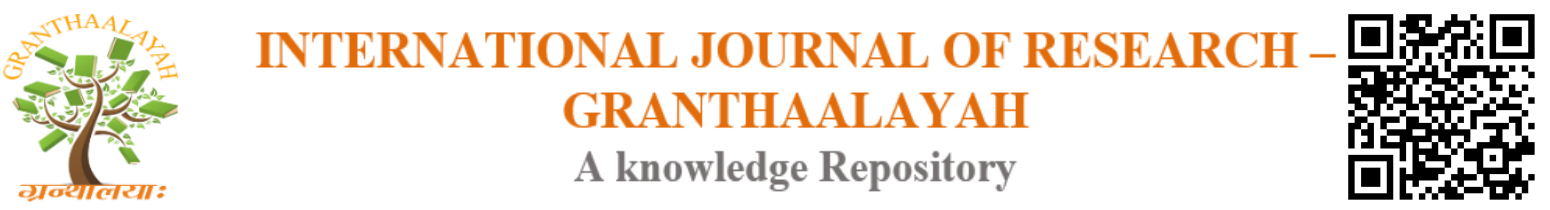

Social

\title{
HAMMACHIISAA: PERSONAL NAMES AND NAMING PRACTICES AMONG THE KUTTAYE OROMO
}

\author{
Merga Feyera Wekjira *1 \\ ${ }^{*}$ (MA), Department of General Linguistics, College of Social Sciences and Humanities, Ambo \\ University, P. O. Box. 19, Ambo, Oromia Region, Ethiopia
}

\begin{abstract}
The paper examined use of personal names and naming practices among Kuttaye Oromo in Ethiopia. Kuttaye names are not just sheer tags, but it provides more approaching into important social, cultural and political events at the time of birth. Furthermore, the paper also discussed the significance attached to Kuttaye personal names. The study is purely qualitative, and a descriptive analysis was made. Purposive sampling was used, and interview and focus group discussion were employed as data collecting instruments.
\end{abstract}

Keywords: Hammachiisaa; Oromo; Kuttaye; Qaalluu; Name; Naming.

Cite This Article: Merga Feyera Wekjira. (2019). "HAMMACHIISAA: PERSONAL NAMES AND NAMING PRACTICES AMONG THE KUTTAYE OROMO.” International Journal of Research - Granthaalayah, 7(9), 110-117. 10.29121/granthaalayah.v7.19.2019.566.

\section{Introduction}

Many researchers stated that Oromo constitutes the largest group in Ethiopia. The Oromos are estimated to comprise $40-50 \%$ of Ethiopia's population of more than 50 million [1]. They live over a large area stretching from close to the Sudan boarder in the West through Addis Ababa (Finfinne), beyond Harar in the East, from Northern Kenya in the South, up and East of the rift valley, and to the Wallo in the North [2]. The Oromo are one of the ethnic groups inhabiting the Horn of Africa, predominantly in Ethiopia. Oromos are one of the most populous nations in Africa and their language, Afaan Oromoo (literally 'mouth of Oromo'), is one of the major indigenous African languages that is widely spoken and used in most parts of Ethiopia and some parts of the neighboring countries [3,4]. The people own age old complex wisdom transmitted dominantly through oral tradition. Scholars who have made extensive study among the society have attested that life philosophies (secular and religious) of the people are engraved in their oral tradition [5].

The basic economic activity of the people is agriculture. The method of agriculture most widely practiced is oxen-drawn plows. Domestic animals include cattle, sheep, goat donkeys, mules, camels and chickens. The main cereal crops are wheat, barley, teff, sorghum, corn etc., and fruits 
include orange, mango, avocado, banana, lemon, etc. The major cash crops are coffee and chat (a stimulant shrub).

Oromo is a group of people that has its own language called Afan Oromo. Many researchers used different terms like Oromo, Afan Oromo, Oromiffa etc to refer the language, but the people recognized the only name 'Afan Oromo'. Afan Oromo is one of the Lowland East Cushitic families of Afro-Asiatic Phylum [2, 6, 7]. Oromo is the third most widely spoken language in Africa after Arabic and Hausa $[8,9]$. Afan Oromo is one of the members of the Cushitic branch of the AfroAsiatic language family, which was the third most widely spoken language in Africa after Hausa and Arabic [10]. Oromo has been considered as one of the 169 critical language of the world [11]. However, within the present day Ethiopia, Afan Oromo is spoken by about 40 percent of the population and is used as a language of inter-group communication in several parts of the country [12].

Oromo is the popular people of the horn that many researchers approved. The Oromo people are one of the most numerous people in Africa [13]. This people is the people that have long history, own age old multifaceted intelligence with its own custom, value, culture, language and its own ruling system. The people are a people that live in the Horn of Africa, especially covering large area and big number of the Ethiopian people.

However, the history of more than a century talks that, as of the other people of Ethiopia, this big people was fallen under the ruling class and lost its system, culture, custom, religion and language. Out of those many cultures and systems the people have been practicing for a long time is 'Hammachiisa'. 'Hammachiisa' is a cultural naming practice by which family of the child give names for the child. It has its own procedure and content. Currently, in addition to the previous political exposure in the country, different religions have been being expanded, and are almost dominating cultural practices like 'Hammachiisaa'. As a result, children born recent years are getting their names according to modern religions, and borrowing names are also dominant. This leads the people to lose their own naming practice. Hence, studying such issue is very crucial, and that is why the study focused on Hammachiisaa: names and naming practices in Kuttaye-Oromo community of Ethiopia.

The study was concerned with Naming in Kuttaye-Oromo. Even though there are many and broad cultural practices in the people, the study dealt with only Hammachiisaa. Procedures, contents and societal values of Hammachiisaa were the concern of the study. Since Kuttaye-Oromo community are very popular in West Shoa, Oromia region- Ethiopia, the study area was also West Shoa specifically, Tokke Kuttaye and Ambo Woredas.

\section{Methodology}

The study was purely qualitative. To attain the planned objective of this study, the following major methodological activities were employed. These activities included data collection and data processing. Data were collected from different sources. To obtain the necessary data for the study, interview and focus group discussion were held in selected study areas. 
The data were collected by using appropriate practitioners of the cultural practice as informants. They were purposely selected, so purposive sampling was utilized to get necessary and appropriate data. Qaalluu institutions of Tokke-Kuttaye were target of the study since it was believed that they are directly the concerned body.

\section{Results and Discussion}

Cultural naming plays very important role in social since the names serve as pivotal roles in societal improvement and renovation. Thus, this paper dealt with how the members of the Kuttaye community took their naming practices into consideration while naming the newly born babies.

\section{Naming in Kuttaye Culture}

The Kuttayes have been naming their newly born children based on their cultural practice. This cultural practice is called Hammachiisaa. Hammachiisaa is a cultural naming practice known in Kuttaye community. The practice was begun by one of the Oromo elders called Gumbu Macca in an antiquity. Since then, it has been being transmitted from generation to generation. However, it is currently dominated and reduced to some specified and limited areas because of different factors. Imported religions and influence of the neighbor culture can be considered as major factors.

\section{When is a Child Named?}

According to the community, a newly born child should be named after forty (40) days of its birth. Hammachiisaa should be carried out on the fortieth day of the birth day. There are two reasons to do it at fortieth day of the birth. The first reason is that the mother of the child cannot move from her home to the place where the practice of Hammachiisaa takes place. The place should be where the Qaalluu leaders live means home of Qaalluu. The Oromo have had an institution called qaalluu to interpret the law of Waaqa and ayyaanaa; Qaalluu is a high priest who was spiritual leader of Oromo traditional religion [14, 15, 16, 17]. Qaalluu leaders are Abbaa Muudaa those that play great role in the Gada System of Ormo. Abbaa Muudaa is a common name of the Qaalluu [17]. The Kuttaye community believes that great care and help should be given for maternal mothers, and that is why mothers should sleep and relax at their home until the fortieth day of the birth day. The second one is that the Qaalluu institutions do not allow females with blood and other natural moisture like ministration to inter the compound of the institution.

Qaalluu leaders play a leading role as name-givers of newly born children. Family of a child should take the child to the home of one of the Qaalluu leaders. This can be done in two ways: one is if the Qaalluu leader is relative of the child's family; second is by prayer (wareega). Both male and female can be Qaalluu Leader, and this tells us that both male and female can lead the Hammachiisaa process.

Nowadays giving names is open to any person irrespective of his family standing. However, Kuttaye traditional naming conventions stress that the most qualified people, as far as naming is concerned, should carry out the practice.

\section{Types of Naming Practices}

The Kuttaye, similar to other Ethiopian people, uses special naming practices to give names to their newly born children. They often grant names based on certain circumstances. In Kuttaye 
culture, for example, names are typically given for children according to the circumstances surrounding the birth of the child, social aspects of the family, hopes, traditional beliefs, and wishes for the child, or the expression of gratitude to a deity.

Kuttaye names are often bestowed upon children with the purpose of remembering their late relatives. Parents may name a child after their late parents because of the love they had for them, thereby feeling as if their parents were still alive. Sometimes children are named after their paternal or maternal relatives because of resembling their physical appearance.

Kuttaye names also reveal the insightful influence the previous ruling body violation has had on their life. Experience shows that the Kuttaye, as a people, cannot be completely free from neighbor cultural contaminate. Naming practices are in one way or another characterized by an acceptance of a hybrid culture in which trans-cultural forms have become the norm. In such a hybrid culture, the Kuttaye draw on both the indigenous resources and neighbor cultural distinctiveness or uniqueness.

\section{Types of Names}

There are many naming customs or practices. In some cultures the name is chosen before the arrival of the child. Others prefer to choose a name immediately after the arrival of the baby.

Since the birth of a child is regarded as a gift, there is a special ceremony in Kuttaye called the traditional ceremony of introducing a newly born child to the general public (Hammachiisaa). This time family should take the child to the home of one of the Qaalluu Leaders. The Qaalluu leader hugs the child and gives name. In this ceremony food like porridge and drinks should be made, and the child is open for viewing by the general public. It is on this special day that the name of the child is made known to the general public. Given the importance of choosing a name, it is appropriate in this study to examine names according to their different categories.

\section{Politically Inspired Names}

Politically inspired names are names that are related to the politics of the day in the country.

These names may relate to political incidents or the activities of politicians and movements needed at the time. Name-givers may choose names of some prominent political leaders whom they wish their children to follow, and names that express situation of the time. Nowadays struggle names and politician names like Qabsoo, Bilisummaa, Birmadummaa, Murataa, Morkataa, Mootummaa, Aangoo, Mararaa, Leencoo etc. are very popular.

\section{Names to Show Misery}

Names can be given to a child whose family members were sick, or whose family member dies during the pregnancy. In order to remember the period and to show their wishes after the coming of the child, the child could be named as Fayyisaa (Male), Fayyisee (Female), Fayyeeraa (Male), Fayyiftuu (Female), Wayyeessaa (Male), Urgeessaa (Male), Urgee (Female), Urgaa'aa (Male). These names show the future wishes of the family for their life. 


\section{Names Which Describe the Child or the Family's Background}

Kuttaye names may reveal a vast degree of information about the Kuttaye as a people. For instance, certain names describe the child's or family's background; mark the activities of the family, record unusual events or the place where the child was born. Names may also mark the interests of the parents, social relationships, and economic life.

\section{When Family Is Poor and Wants to Express Their Future Wishes}

Name can also express status of family in terms of economy. The community consider child as a symbol of prosperity. When a child is born in family that has weak economic status, the family can name the newly born child as Ukaa (Male), Hirkoo (Male), Abdii (Male), Abdiisaa (Male), Abdataa (Male), Abdannee (Female), Gaaddisee (Female), Gaaddisaa (Male), Gaaromsaa (Male), Namoomsaa (Male), Olaansaa (Male), Olumaa (Male), Mul'isaa (Male), Barnabaas (Male) etc. to state that even though they are currently in poor status, prosperity will also come after the child comes.

\section{To Mark Number of Children}

Having many children is popular in the community. When they get many children they give names like Baay'isaa, Mirreessaa, Cimdii, Cimdeessaa, Camadaa for male and Baay'isee for female, etc. to express as they have many children.

\section{To Express Beauty}

The community has also a culture of admiring beauty, and uses different ways of expressing their passion towards it. One of the popular ways of expressing beauty is the use of names. Names like Ilillii (Female), Simboo (Female), Simbirroo (Female), Bareedduu (Female), Kuulanii (Female), Meetii (Female), Warqee (Female) etc. are those that are used in the community to admire beauty of the born child.

\section{To Express as Child Is Gift of God}

Kuttayes believe that children are gift of God. They bestow the newly born child as Waaqjiraa (Male), Rabbumaa Male), Tolawaaq (Male), Kennawaaq (Male), Eebbawaaq (Male), Waaqasaa (Male), Waaqwayyaa (Male), waaqumaa (Male), Waaqoo (Male) to express how much God love them.

\section{To Express Wishes}

The community has especial place for children. They have great love and ambitions for their children, and one of the ways they use to express their passion is through naming. The following are names that show wishes that family has for its child; these are: Margaa (Male), Margee (Female), Margituu (Female), Magarsaa (Male), Magartuu (Female), Lalisee (Female), Lalisaa, (Male) Lataa (Male), Lattuu (Female), Biqilaa (Male), Biqiltuu (Female), Biqilee (Female), Caalaa (Male), Caaltuu (Female), Caalchisaa (Male), Caalchisee (Female) etc.

\section{To Express Value of Child}

The Kuttayes have special value for children. Children are considered as very important person in their life, and to depict this they can name their children as Firaa'ol, Firaanboon, Firrisaa, Firaatol. 


\section{When a Child is Added}

Anyone can have more children in the community. Hence, when a child is male names like Lamnmeessaa, Dabalaa, Kumaa, Kumasaa can be given; when it is female Dabaltuu, Dabalee, Kumashii are the popular names given for the child.

\section{To Admire Communion}

The community also believes that unity is power and strength, and tries teaching it in different ways. Giving names that express unity is one way the community uses. Names like Gurmuu, Tokkummaa, Gurmeessaa, Gamtaa are some popular names that are used to create and strength bond among the people.

\section{Names from System and Festivals}

There are popular systems and festivals practices in the community. In connection with this, names of children that born on the days of the festivities can be taken from the names of the systems and festivals. Names like Gadaa, Ateetee, Ayyaanaa, Ayyaantuu etc are taken from popular systems and festivals of the community.

\section{Mercy}

If there is disagreement among members of the family before the coming of the child, and agreement is made after the event, the child could be named as Araarsaa, Firoomsaa, Taasisaa for male and Araarsee, Firoomsee and etc for female.

\section{Names used to Express Fate of The Child}

The community believes that a newly born child always comes with its own destiny. Whether they are in good or bad condition, they wish their children born with their fate. Hence, they express the feeling by naming the newly born child as Tolasaa, Tolaa, Gaarummaa, Qajeelaa, Guddisaa, Guddataa, Guddaa for male, and Guddattuu, Guddisee, Toltuu, Tolashii for female.

In addition to Hammachiisaa, different ways of giving names are also being practiced in the community. This happens because of different reasons like language and religious contact.

\section{Borrowing names}

Amharic is a neighbor language for Afan Oromo speakers, and it has been serving as the ruling language in the country. This creates for the community the opportunity to be bilingual. As a result, names like Abarraa, Dammallaash, Alamaayyoo, Baqqalaa, Balaay, Biraanuu, Wandimmuu, Mangistuu for male, and Tigist, Abarraash, Taaddaluu, Geexee etc for female are also taken from Amharic language, and are given for children.

\section{Christian Names}

Christian names are given to children in accordance with their parents' religious beliefs. These names are in most instances currently associated with the parents who have accepted Jesus Christ as their Saviour, and who believe that their offspring will follow in the footsteps of Jesus Christ. Both maternal and paternal families do participate in giving a child a Christian name. Children may be given names such as Saamsoon, Hayilasillaasee, Hayilayyasuus, Hayilamikaa'el, Hayilamaaram, Daani'el, Maariqoos, Maatiwoos, Dibooraa, Maaramii, Yaaseef. 


\section{Conclusion}

The paper has focused on personal names and various naming practices among the Kuttaye community. It has been stressed that naming an individual is considered as an important event; hence names are sometimes determined by the need to be responsible for the names of some family members. Both the living and dead members' names are considered in naming a newly born child. The choice of such names is equally influenced by the desire to honor the family members. This indicates that the living and the departed have a special place in the family's history. From a traditional point of view, naming a child after some outstanding or revered person is regarded as an honor to the child in that it is believed that the name-bearer would grow to emulate that particular prominent figure. The paper has also shown that by perpetuating the name of a family member, the family concerned is in one way or another trying to create a positive and mutual relationship among its members. The paper has also shown that naming a newly born child is not independent of the society in which events occur. The circumstances surrounding a child's birth account for a variety of reasons behind the naming of children.

\section{Recommendations}

It is recommended that the name-givers should make use of naming practices with the definitive aim of enhancing the Kuttaye tradition, culture and custom. This will make sure that the young generation will know and be proud that their tradition, culture and customs are of paramount important.

\section{References}

[1] Edmond J. Keller (1995). The Ethnogenesis of the Oromo Nation and its Implecations for Politics in Ethiopia. The Journal of Modern African Studies, 33, 4 (1995), pp. 621- 634.

[2] Gragg, G.1982. Oromo Dictionary, Bender et.al. (eds.) and East Lansing: The African Study Center, Michigan State University.

[3] Hassen, M. (1990). The Oromo of Ethiopia: A History 1570-1860. Red Sea press.

[4] Gadaa Malbaa (1980). Oromia: A Brief Introduction. Finfinnee: Oromia.

[5] Bulcha, M. (1994). "The Language policy of Ethiopian Regimes and the History of Written Afaan Oromo: 1884-1994". The Journal of Oromo Studies Vol. 1(2): 91-115

[6] Bender and Mulugeta (1976). The Non-Semitic Languages of Ethiopia East Lansing: African Studies Center, Michigan State University.

[7] Baye, 1986:8). The Phrase Structure of Ethiopian Oromo. The Degree of $\mathrm{PhD}$ in Linguistics, School of Oriental and African University of London.

[8] Gadaa Malbaa (1988). Oromia. Sudan, Khartoum.

[9] Mahdi Hamid Muudee .1995. Oromo Dictionary, English-Oromo, Vol. I. Atlanta, Georgia: Sagalee Oromo Publishing Co.

[10] Workineh Tesema et.al. (2017). Investigating Afan Oromo Language Structure and Developing Effective File Editing Tool as Plug-in into Ms Word to Support Text Entry and Input Methods. American Journal of Computer Science and Engineering Survey. AJCSES [1][01] [2017]001-008

[11] Crystal, D.1987. The Cambridge Encyclopedia of Language. Cambridge: Cambridge, University Press.

[12] Kebede Hordofa, 2009. Towards the Genetic classification of the Afan Oromo Dialects. The Doctor of Philosophy Deree in Linguistics, The University of Oslo. 
[13] Baxter, P.T.W. et.al. (1996). Being and Becoming Oromo: Historical and Anthropological Enquiries. Nordiska Afrika Institutet, Uppsala.

[14] Mohammed Hussen (1990). The Oromo of Ethiopia: A History 1570 - 1860. New York: Cambridge University Press.

[15] Knutsson, Karl Eric (1967). Authority and Change: A study of the k'allu Institution Among the Macha Galla of Ethiopia. Goteborg

[16] Lewis, Herbert S. (1990). "Gada, Big Man, K'allu: Political Succession among the Eastern Mech'a Oromo". In Northeast African Studies, Vol.12, No. 1. pp 43-64. East Lansing: Michigan State University.

[17] Asmerom Legesse (1973). Gada: Three Approaches to the study of African Society. London: The Free Press.

*Corresponding author.

E-mail address: margaa30fayyoo@ gmail.com 